\title{
MICROSTRUCTURAL ANALYSIS OF SINTERED GRADIENT MATERIALS BASED ON DISTALOY SE POWDER
}

\begin{abstract}
The study describes the microstructural analysis of cylindrically-shaped fumctionally graded products sintered from iron powder with scheduled graded structure on the cross-section running from the core to the surface layer of the sinter. Different types of structure were produced using Distaloy SE powder in two compositions - one without the addition of carbon, and another with $0.6 \mathrm{wt} \% \mathrm{C}$. Two methods were used to fill the die cavity and shape the products. The first method involving a twostep compaction of individual layers. The second method using an original technique of die filling enabled the formation of transition zone between the outer layer and the core still at the stage of product shaping. As part of microstructural analysis, structural constituents were identified and voids morphology was examined. Studies covered the effect of the type of the applied method on properties of the graded zone obtained in the manufactured products

Keywords: functionally graded materials (FGM), powder metallurgy (PM), low-alloy steels
\end{abstract}

\section{Introduction}

Production of structural functionally graded materials by the technology of powder metallurgy allows for the combination of components with different properties unattainable by traditional manufacturing technologies. In this way it is possible to obtain materials with the graded structure of the previously scheduled orientation. Changes in the structure can occur abruptly, gradually or continuously, depending on the needs or capabilities. The purpose is to obtain a product with the surface characterized by high mechanical or thermal resistance, or improved corrosion resistance, or abrasive wear resistance, and core that preserves completely different properties, e.g. ductility and high dynamic resistance. The possibility of obtaining the graded structure, previously scheduled and adjusted to specific applications, largely depends on the individual thermomechanical properties of the joined materials, which affect the course of the entire manufacturing process starting with forming, through sintering and in final heat treatment, plastic working or mechanical finishing ending.

The method used most commonly for designing of material functionality consists in shaping the outer layer of products. This is done by various traditional methods, such as e.g. strengthening by plastic forming (burnishing, rolling), or by combined thermal and chemical treatment. In recent years, new technologies have emerged for the application and shaping of surface layers to mention, among others, diffusion and laser techniques, casting, infiltration and welding $[1,2]$. An important group of materials includes steels which have the surface layer modified by ceramic materials produced with the use of laser energy $[3,4]$. A separate group is composed of functional materials used for all kinds of medical implants. These materials, called biomaterials, should offer sufficient strength, biocompatibility and biotolerance, all this combined with high corrosion resistance. Examples of such materials are AISI316L steel- HA composites made by the technique of powder metallurgy [5].

The techniques of compacting and sintering different compositions of materials continue being the relevant and frequently applied processes for the fabrication of functionally graded materials. They allow shaping the structure gradient not only through diffusion during sintering, but also at the stage of consolidation, using various methods of sedimentation [6] or through application of centrifugal force [7]. The latest technologies for forming and sintering of functionally graded products include the SPS (Spark Plasma Sintering) method combining the pulse DC current heating and pressure effect [8].

To combine two materials with different thermal and mechanical properties requires careful designing of individual zones, mainly to ensure proper transition between them. The expected graded structure and properties are obtained by appropriate relative proportions of individual materials used in the powder mix. Any simplification introduced to the technology of making graded structures is an important step forward and has so far been achieved by various methods, some of which are discussed in the present study. The formation of a transition zone in sinters is very easy when obtained through diffusion process during heat treatment, provided that the applied sintering time is long enough. This is particularly important when the composition of processed materials comprises various elements that are characterized by different values of diffusivity. In such cases, the intermediate layers are made by successive compaction of powder materials mixed in appropriate proportions.

This article presents the results of studies, which as a main aim have the development of a technology for the manufacture

* CRACOW UNIVERSITY OF TECHNOLOGY, INSTITUTE OF MATERIALS ENGINEERING, FACULTY OF MECHANICAL ENGINEERING, 24 WARSZAWSKA STR., 31 -155 KRAKÓW, POLAND

\# Corresponding author: kazar@mech.pk.edu.pl 
of cylindrically-shaped functionally graded products, where the developed technology allows for the formation of transition layer during charging of a cylindrical die, still before compaction preceding the pressureless sintering process. Another aim of the conducted studies was identification of structural constituents in individual product areas. Basing on the obtained results, the properties of the intermediate graded layer were determined and the usefulness of the developed technology as a tool to produce materials of the scheduled functionally graded structure and properties was estimated.

\section{Test material}

Distaloy SE powder manufactured by Höganäs SA was used. The powder is an equivalent of low-alloy structural steel. It is produced from a sponge iron powder, is very easily mixed with graphite and achieves high strength in as-sintered condition. It is often used in the fabrication of engineering products undergoing final heat treatment. For the purpose of this study, two powder mixes were prepared. Mix A of the base chemical composition and mix B with $0.6 \mathrm{wt} \%$ addition of carbon in the form of synthetic graphite of the trade name Timrex F10 PM Special Graphite designated as N-010. Both mixes were enriched with $0.5 \mathrm{wt} \%$ addition of the Kenolube P11 slip agent. To mix B it was added after mixing the powder with graphite. Mixing was carried out in a rotary mixer for 3 hours. The chemical composition of Distaloy SE powder taken from the data provided by the manufacturer as well as the composition of respective mixes and the density values determined by pycnometry are presented in Table 1 .

The ready powder mixtures were used to make cylindrical samples with a height-to-diameter ratio close to unity $(\mathrm{h} / \mathrm{d} \approx 1)$, (Fig. 1). The specimen core of $\varphi 16 \mathrm{~mm}$ diameter was made from a carbon-free mix (mix A). The outer layer was made from a mix with the addition of carbon (mix B). Adopting the specimen dimensions given in Figure 1 and taking into account the required volume of both mixes, the average density was determined by pycnometry and it was found to be $\mathrm{rt}=7.749 \mathrm{~g} / \mathrm{cm}^{3}$.

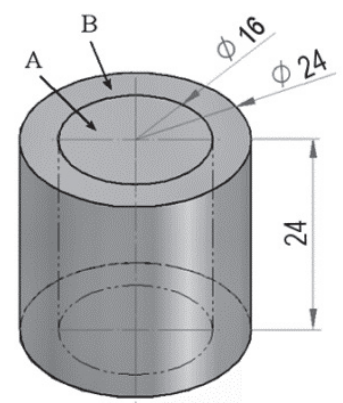

The selected composition of powder mixes gave products composed of a $4 \mathrm{~mm}$ thick, hard and resistant, outer layer with a $16 \mathrm{~mm}$ diameter core of lower strength. The weight of both mixes was calculated assuming the same density of the core and outer layer and final post-compaction porosity amounting to $\Theta_{\mathrm{k}}=0.05$.

The difference in the process of sample fabrication consisted in the technique of filling the die cavity prior to uniaxial double-side pressing. In the first variant, the outer layer of the sample was subjected to a single-side pre-compaction with a pressure of $15 \mathrm{MPa}$ (Figs. $2 \mathrm{a}$ and $2 \mathrm{~b}$ ) performed around a mandrel placed in the die, where the mandrel diameter was the same as the diameter of the sample core. The value of the initial pressure was chosen experimentally in such a way as to confer to the outer layer adequate density ensuring its cohesion at the moment of the mandrel withdrawal from the die. After the withdrawal of the mandrel (Fig. 2c), the die was filled and single-side compaction was applied to the core first (Figs. 2c, 2d), and to the entire sample next (Fig. 2e). Final compaction was performed by the method of double-side pressing using a floating die mounted on a spring of properly selected stiffness.

a)

b)

c)

d)

e)
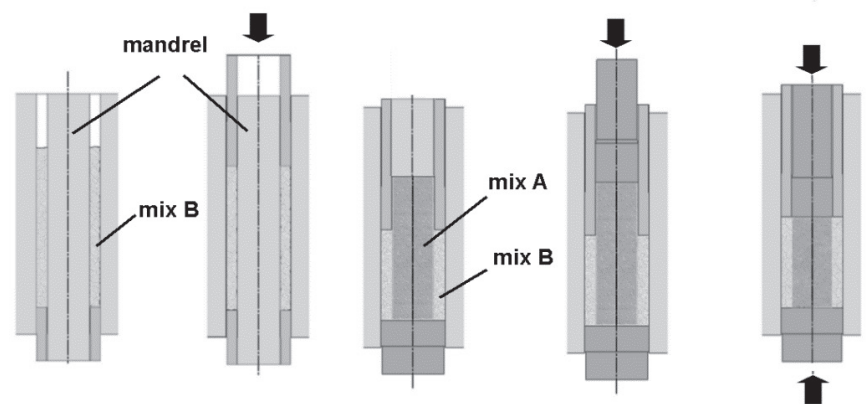

Fig. 2 Schematic diagram of sample pressing according to mode I with pre-compaction:

a) Filling of die to produce an outer layer around the mandrel; b) Pre-compaction of the outer layer; c) Filling of the sample core; d) Pre-compaction of the sample core; e) Final compaction

An alternative die charging technique comprised filling of the die with two separate layers of different mixes, where the core powder was placed in a special container whose walls separated the two materials (Figs. $3 \mathrm{a}$ and $3 \mathrm{~b}$ ). The withdrawal of the container (Fig. 3c) caused the detachment and falling down of powder particles along the container walls with the successive formation of a mixed material zone $\mathrm{A}+\mathrm{B}$. The final step was simultaneous, double-side compaction of both mixes in a floating die in a way similar to the method described previously.

Fig. 1. The specimen

TABLE 1

Chemical composition of Distaloy SE and the composition of powder mixtures A and B

\begin{tabular}{|c|c|c|c|c|c|c|c|c|c|}
\hline \multirow{3}{*}{$\begin{array}{l}\text { Mix } \\
\text { code }\end{array}$} & \multicolumn{8}{|c|}{ Content in wt \% } & \multirow{3}{*}{$\begin{array}{l}\text { Theoretical density } \\
{\left[\mathrm{g} / \mathrm{cm}^{3}\right]}\end{array}$} \\
\hline & \multirow{2}{*}{$\begin{array}{c}\mathrm{C} \\
\text { (graphite) }\end{array}$} & \multirow{2}{*}{$\begin{array}{l}\text { Kenolube P11 } \\
\text { (slip agent) }\end{array}$} & \multirow{2}{*}{ Distaloy SE } & $\mathrm{Cu}$ & $\mathrm{Ni}$ & Mo & $\mathrm{C}$ & $\mathrm{Fe}$ & \\
\hline & & & & 1.50 & 4.00 & 0.50 & 0.01 & rest & \\
\hline A & 0.00 & 0.50 & & & $\mathrm{re}$ & & & & 7.801 \\
\hline $\mathrm{B}$ & 0.60 & 0.50 & & & $\mathrm{re}$ & & & & 7.708 \\
\hline
\end{tabular}


a)

b)

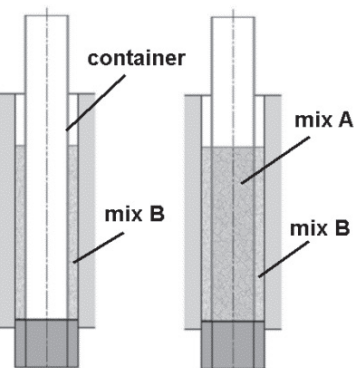

d)

e)

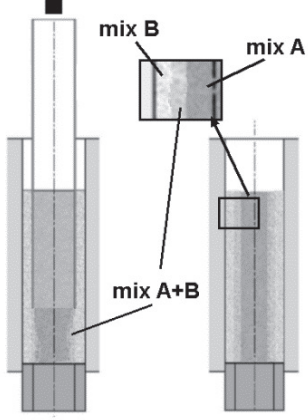

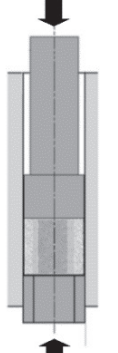

Fig. 3. Schematic diagram of sample pressing according to mode II filling of die with the use of container:

a) Filling of die to produce an outer layer around the container; b) Filling of container; c) and d) Removal of container from the die; e) Final compaction

All products were sintered by pressureless technique in a 6.0 hydrogen atmosphere at a temperature of $1120^{\circ} \mathrm{C}$ for a time of 30 minutes. Some of the samples were hardened immediately after sintering by the, so called, sinter-hardening method. Cooling was carried out in oil at a temperature of $860^{\circ} \mathrm{C}$. The measurements showed that the rate of cooling from $860^{\circ} \mathrm{C}$ to $300^{\circ} \mathrm{C}$ was at a level of $30^{\circ} \mathrm{C} /$ sec. Schematic diagrams of the applied heat treatment are plotted in Figure 4.

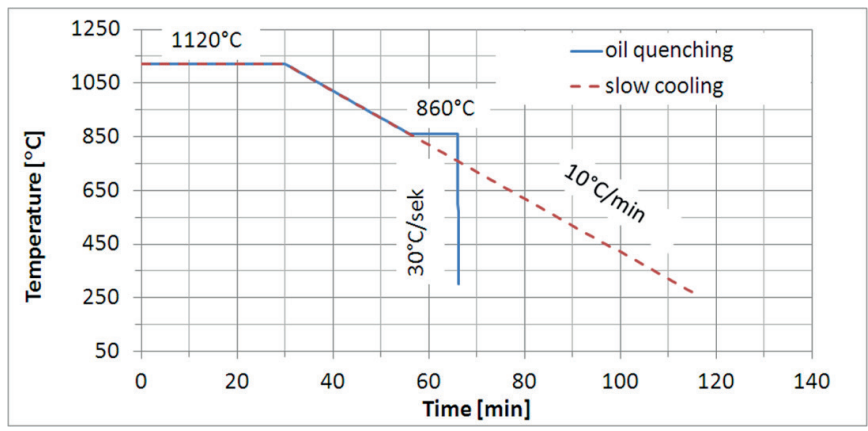

Fig. 4. Schematic diagram of the applied heat treatment:a) heating and cooling at a rate of $10^{\circ} \mathrm{C} / \mathrm{min}$; b) heating at a rate of $10^{\circ} \mathrm{C} / \mathrm{min}$ and cooling in oil from the temperature of $860^{\circ} \mathrm{C}$ at a rate of $30^{\circ} \mathrm{C} / \mathrm{sec}$.

\section{Research methodology}

Samples prepared by the two, previously described, different methods of die charging and heat treatment were subjected to further studies to identify the individual microstructural constituents. Table 2 shows sample codes depending on the method of fabrication and heat treatment type.

TABLE 2

Identification of samples

\begin{tabular}{|c|c|c|c|c|}
\hline \hline \multirow{2}{*}{$\begin{array}{c}\text { Performance and } \\
\text { treatment }\end{array}$} & \multicolumn{2}{|c|}{$\begin{array}{r}\text { Pre-compaction15 } \\
\text { MPa }\end{array}$} & \multicolumn{2}{c|}{ Pressing on-time } \\
\cline { 2 - 5 } & Sintering & $\begin{array}{c}\text { Sinter- } \\
\text { hardening }\end{array}$ & Sintering & $\begin{array}{c}\text { Sinter- } \\
\text { hardening }\end{array}$ \\
\hline Sample code & I.S & I.H & II.S & II.H \\
\hline
\end{tabular}

The following tests and examinations were performed:

- Determination of average density by gravimetric method.

- Analysis of porosity using image analyser, including determination of the shape and distribution of pores.

- Distribution of microhardness HV 0.1 (Innovatest 423A microhardness tester).

- Microstructural analysis done by optical microscopy (Nikon Eclipse ME600P microscope).

- Microstructural analysis and microanalysis of chemical composition done by scanning electron microscopy (JSM-820 scanning electron microscope made by JEOL equipped with an EDS analyser).

Studies of microhardness, besides the distribution of microhardness values on the cross-section of selected samples, were intended to confirm the different properties of the core and outer layer, and facilitate the identification of microstructural constituents in various sections of the sample. Measurements of microhardness and porosity were discretized using a measuring grid according to the schematic diagrams drawn in Figures 5a and 5b.
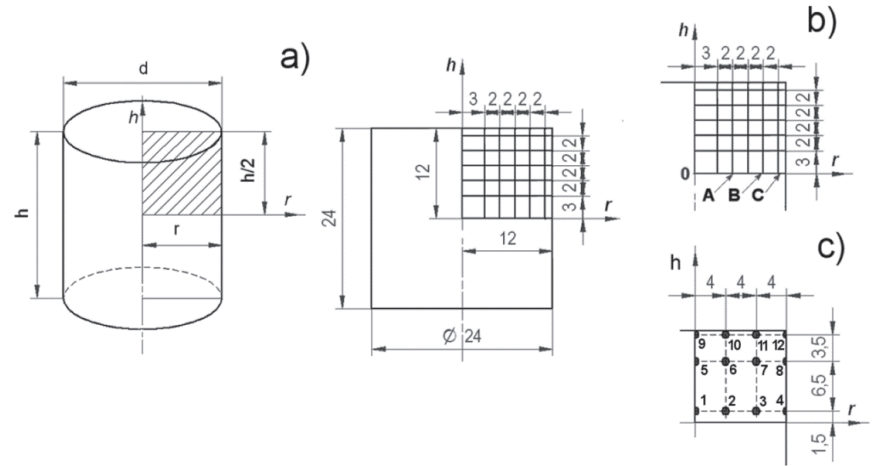

Fig. 5. Measuring grids for: a) microhardness measurement; b) microstructure analysis; c) porosity measurement

From the ready specimens, metallographic sections were prepared. Metallographic examinations were carried out by optical microscopy and SEM. Porosity measurements were taken on unetched specimens, while microstructural constituents were examined on the specimens etched with $4 \%$ nital solution.

\section{Discussion of results}

The results of porosity and microhardness measurements were presented as mean values with the confidence intervals \pm $\mathrm{t}_{\alpha, \mathrm{f}} * \mathrm{~s}(\overline{\mathrm{x}})$ for the adopted level of significance $\alpha=0,1$ (where $\mathrm{s}$ $(\overline{\mathrm{x}})$ - the standard deviation of the arithmetic mean, $\mathrm{t}_{\alpha, \mathrm{f}}$ - the critical value derived from the Student's t-distribution).

The results of the average density measurements taken on samples after compaction and sintering and of the apparent porosity after sintering and heat treatment (for selected samples) are given in Table 3 . The average density was measured by a geometric method.

Samples of I.H and II.H type were used to determine the effect of the two developed manufacturing methods on the microstructure of products and properties of the gradient 
zone. Microhardness of II.S and II.H products was compared to determine the effect of heat treatment on the mechanical properties of sinters.

\subsection{Microhardness measurements}

Graphs in Figure 6 show the distribution of microhardness HV 0.1 values on the cross-section of samples, measured at the grid points according to a scheme illustrated in Figure 5a for products designated as II.S and II.H. The graph in Figure 7 shows average microhardness values obtained for these products.
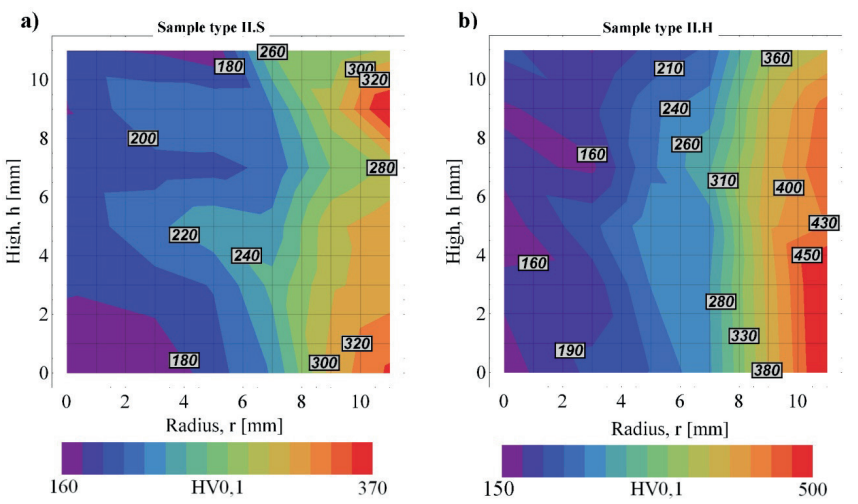

Fig. 6. Microhardness distribution in samples: a) II.S (pressure of 800 $\mathrm{MPa}$ );b) II.H (pressure of $800 \mathrm{MPa}$ )

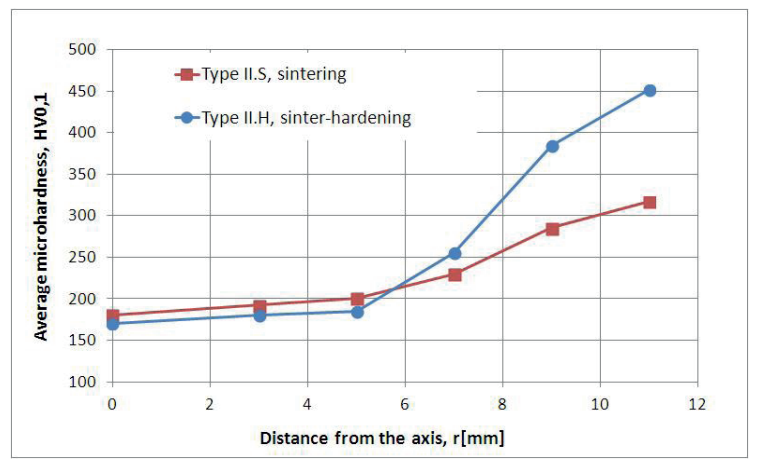

Fig. 7. Microhardness distribution in samples: a) II.S;b) II.H (pressure of $800 \mathrm{MPa}$ )

High nickel content in the composition of Distaloy SE powder is the reason why after sintering and heat treatment the structure of the obtained sinters was heterogeneous and composed of several structural constituents as proved by the microstructural analysis described in further part of this study. Similar microstructure was observed in sinters based on Distaloy AE powder [9] of similar chemical composition. Microhardness measurements covered all structural constituents found in the area close to the measuring point. The numerous nickel-rich areas (NRA) were characterized by low hardness. The highest hardness was recorded in the areas composed of martensite and bainite. The distribution of microhardness on the sample cross-section (Fig. 6) has indicated that, as expected, in samples processed by the "sinter-hardening" method, hardness of the surface layer was higher compared with products that were only sintered. This is also confirmed by a graph of the average microhardness values plotted as a function of the distance from the sample axis (Fig. 7). The cores of products after both types of the heat treatment had similar mechanical properties - inferior to the surface layer. Considering the need to carry out the hardening treatment in order to obtain sufficiently high mechanical properties of the surface layer, further observations and analysis were done on samples taken from the products treated by "sinter-hardening".

\subsection{Morphology of voids}

The main characteristics that decide about the mechanical and functional properties of products fabricated from the sintered metal powders of selected chemical composition include final density, microstructure, and morphology of voids. A quantitative analysis of the morphology of pores, including their size and shape, was carried out determining the following stereological parameters:

- $\quad$ the size of pores calculated from the sectional area $a\left[\mu_{\mathrm{m}}{ }^{2}\right]$,

- the dimensionless shape (circularity) factor calculated from the relationship:

$$
f_{1}=\frac{4 \cdot \pi \cdot A}{L^{2}}
$$

where: A - the surface area of the examined object, L the circumference of the examined object. For a circle $\mathrm{f}_{1}=1$, for other figures $\mathrm{f}_{1}<1$;

- the corrugation ratio (solidity factor) defined by a ratio of the object surface to the surface of a convex hull or convex polygon circumscribing this object; for a circle $=$ 1 , for other figures $<1$;

$$
f_{2}=\frac{A}{A_{1}}
$$

where: A - the surface of the examined object, $A_{1}$ - the surface of a convex hull surrounding this object. For a full circle $\mathrm{f}_{2}=1$, for other figures $\mathrm{f}_{2}<1$.

The results of measurements of the sample density and apparent porosity. after compaction and sintering

\begin{tabular}{|c|c|c|c|}
\hline Sample code & $\begin{array}{c}\text { Compaction pressure P } \\
{[\mathrm{MPa}]}\end{array}$ & $\begin{array}{c}\text { Average density after } \\
\text { sintering } \rho\left[\mathrm{g} / \mathrm{cm}^{3}\right]\end{array}$ & $\begin{array}{c}\text { Apparent porosity after sintering } \Theta(\text { the theoretical density } \\
\left.\text { adopted in tests was } \rho_{\mathrm{t}}=7,749\left[\mathrm{~g} / \mathrm{cm}^{3}\right]\right)\end{array}$ \\
\hline I.H & 800 & $7.27 \pm 0.01$ & $0.06 \pm 0.01$ \\
\hline II.S & 800 & $7.28 \pm 0.01$ & $0.06 \pm 0.01$ \\
\hline II.H & 800 & $7.27 \pm 0.02$ & $0.06 \pm 0.01$ \\
\hline
\end{tabular}


Porosity structure was determined for products made by the two compaction techniques. Examinations covered areas of the size of $860 \times 640$ pixels, each corresponding to the actual surface area of a metallographic section of the size of $0.95\left[\mathrm{~mm}^{2}\right]$. Stereological measurements of the structure were taken by the method of planimetry. For each examined case, the number of areas was selected in such a way as to ensure the inclusion of a total of over 6000 objects (pores). The assumed level of significance was $\alpha=0.05$. The results of porosity analysis are given in Table 4, while graphical representation is depicted in Figure 8.

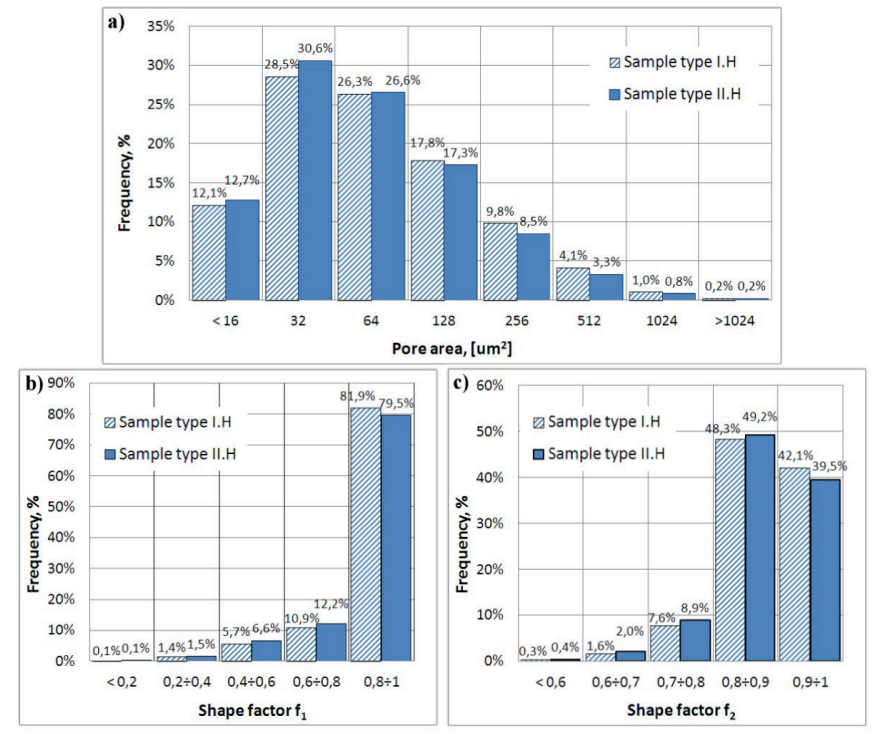

Fig. 8. The distribution of porosity parameters: a) the distribution of pore area; b) the distribution of circularity; c) the distribution of solidity

TABLE 4

Average values of shape parameters

\begin{tabular}{|c|c|c|c|}
\hline \hline \multirow{2}{*}{$\begin{array}{c}\text { Sample } \\
\text { code }\end{array}$} & $\begin{array}{c}\text { Pore area } \\
{\left[\mu \mathrm{m}^{2}\right]}\end{array}$ & Circularity, $f_{l}$ & Solidity, $f_{2}$ \\
\hline I.H & $78.2 \pm 1.1$ & $0.905 \pm 0.001$ & $0.890 \pm 0.001$ \\
\hline II.H & $72.4 \pm 1.0$ & $0.895 \pm 0.001$ & $0.738 \pm 0.001$ \\
\hline
\end{tabular}

Regardless of the method of compaction, i.e. with precompaction or without, the morphology of voids in resultant products does not show any more significant differences. The average size of voids, their distribution and shape are similar. Pores of circular shapes prevail, as evidenced by the average circularity coefficient for both types of products and $80 \%$ occurrence of pores with the value of this coefficient comprised in a range of $1 \div 0$.9. The solidity factor describing voids in terms of the development of their surface indicates the preferred average value of this parameter $f_{2}=0.89$ and above $90 \%$ occurrence of all pores with the value of this factor above 0.8 .

\subsection{Microstructural analysis}

The aim of microstructural analysis was to identify structural constituents in various areas of the sintered products according to the diagram shown in Figure $5 \mathrm{~b}$. Samples of both I.H and II.H type were included. The cores of the samples made of mix A had a ferritic structure. During sintering, the increased nickel content and hindered interdiffusion of iron and nickel [10] resulted in the formation of nickel-rich areas visible in the microphotographs as light-colour, hardly etched patches $[11,12]$. They occur most frequently in the vicinity of pores and are present in parts of product made from mixes A and B. Figure 9 shows an area lying close to the point located at a half-height and distant by about $5 \mathrm{~mm}$ from the sample axis (point $\mathrm{A}$ - the core made of a carbon-free mixture). Visible is the ferritic structure with numerous NRA areas. The picture shows indentation marks and values obtained during the measurement of microhardness HV0.1.

After heat treatment, the outer layer made of mix B acquires the microstructure composed mainly of martensite and bainite with small amounts of pearlite. Knowing the nickel ability to stabilize austenite to room temperature, the bright areas can be identified with this particular structural constituent. Microhardness tests have shown that they are „soft" compared with martensite or bainite. Figure 10 shows micrographs of the area located at a half-height and $9 \mathrm{~mm}$ distant from the sample axis (point B - the outer layer around a transition zone). The material in this part of the sample contains the addition of $0.6 \% \mathrm{C}$. Visible are light-colour areas rich in nickel and minor amounts of retained austenite.
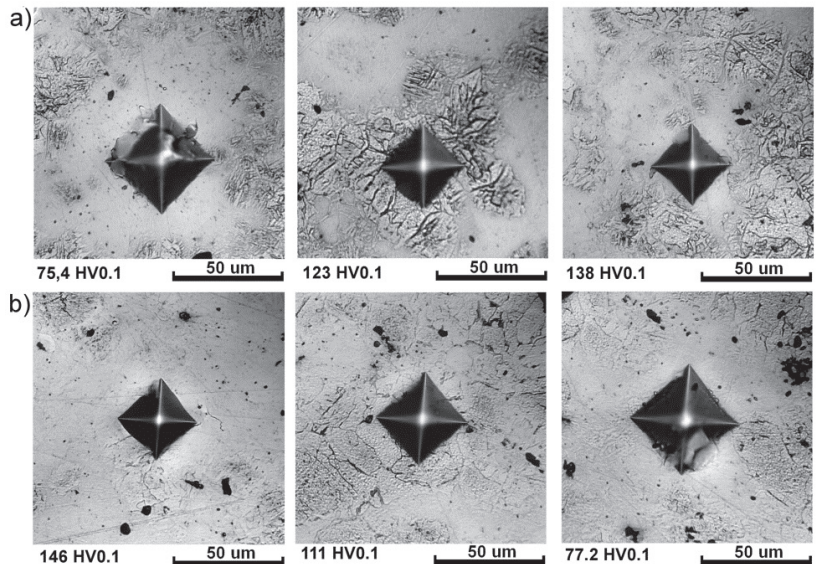

Fig. 9. Optical micrograph of sample: a) I.H;b) II.H: Area at point A etched with Nital
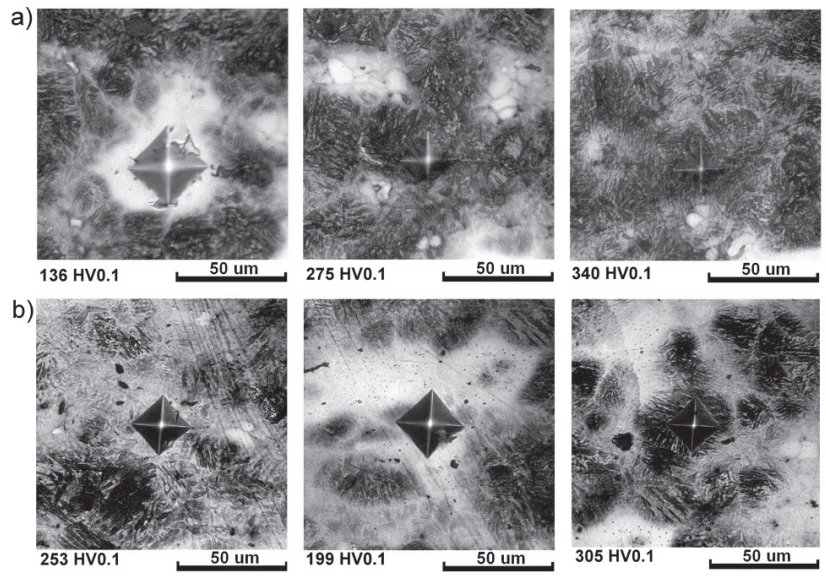

Fig. 10. Optical micrograph of sample: a) I.H;b) II.H: Area at point $B$ etched with Nital. 
Figure 11 shows the microstructure of a sample at a location $1 \mathrm{~mm}$ distant from the surface (point $\mathrm{C}$ - the outer layer). Here again is visible the structure composed of bainite and martensite. The results of hardness measurements indicate the presence of martensite with carbon content higher than in the vicinity of transition zone, where carbon content is lower due to blending of two powder compositions during filling of the die and diffusion taking place during sintering.
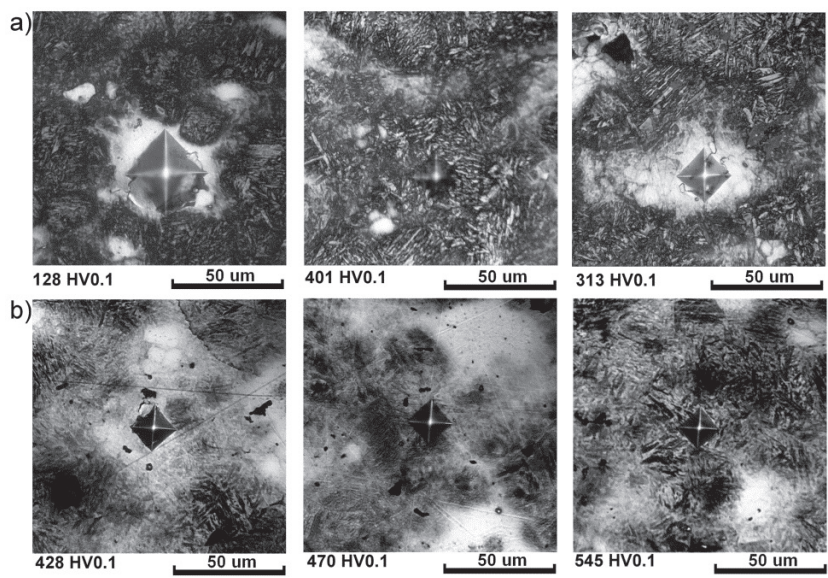

Fig. 11. Optical micrograph of sample: a) I.H;b) II.H: Area at point C etched with Nital.

To confirm the nature of the bright and hardly etched fields visible under an optical microscope and identified as nickelrich areas, an EDS chemical analysis, including linear scanning and mapping, was made. Figure 12a shows an example of the analysis performed along a line marked in the drawing, while Figure $12 \mathrm{~b}$ shows mapping of areas occurring in the same place, i.e. near point B (according to diagram in Fig.5b). The results of both examinations have revealed an increased nickel content in the areas of a uniform grey colour, visible under an optical microscope as bright fields and identified as NRA.
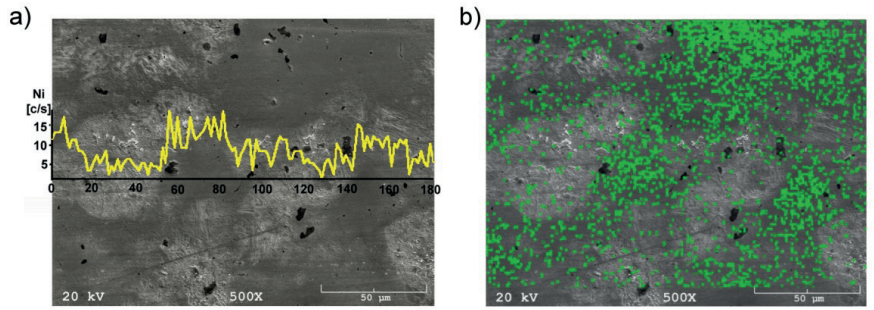

Fig. 12. The results of EDS analysis of the nickel distribution. Sample of II.H type, area at point B ; a) linear scan; b) mapping

The microstructure of the sinter made from mix A was identified as ferritic, whereas in the case of mix B it consisted of martensite, bainite and pearlite. In sinters of the IH type, the transition zone between the core and the outer layer was formed only by diffusion, which occurred during sintering. Due to the special technique of die filling, in products of the II.H type, the gradient in the transition zone was formed as a result of the two powders getting mixed together, with ultimate carbon content in the material varying and dependent on the end proportions of mixes A and B. At further stages of the process, the effect of diffusion was observed, and hence the resulting sintered structure had different share of the individual structural constituents. Therefore, the microstructural analysis evaluating the properties of a transition zone also included the determination of the contribution of structure characteristic of mix $B$ in individual cross-sectional areas of the manufactured products. As a measure of the microstructure gradient was adopted the increase in the share of the structure composed of martensite, bainite and pearlite examined as a function of the distance from the sample axis. In the image of microstructure obtained by optical microscopy these constituents are darker than the ferrite of which the product sintered from carbon-free powder is mainly composed. Figure 13 shows a panoramic view of photomicrographs comparing the functionally graded structure of the sintered products of the I.H (Fig. 13a) and II.H (Fig. 13b) type. Figure 14 shows the average share of martensitic-bainitic-pearlitic structure as a function of the distance from product axis.

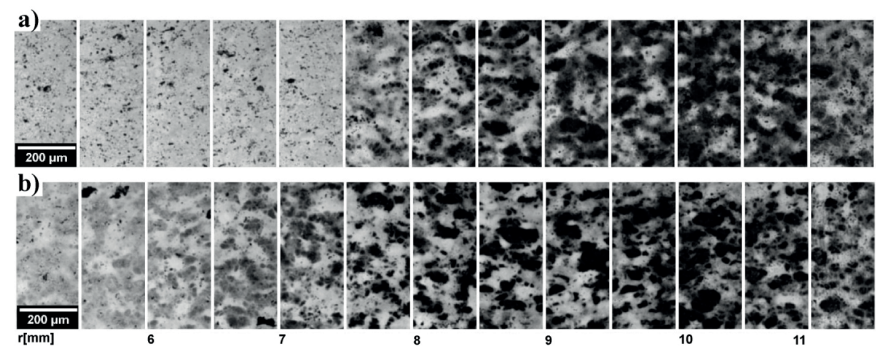

Fig. 13. Image of the functionally graded structure in products: a) I.H and b) II.H.

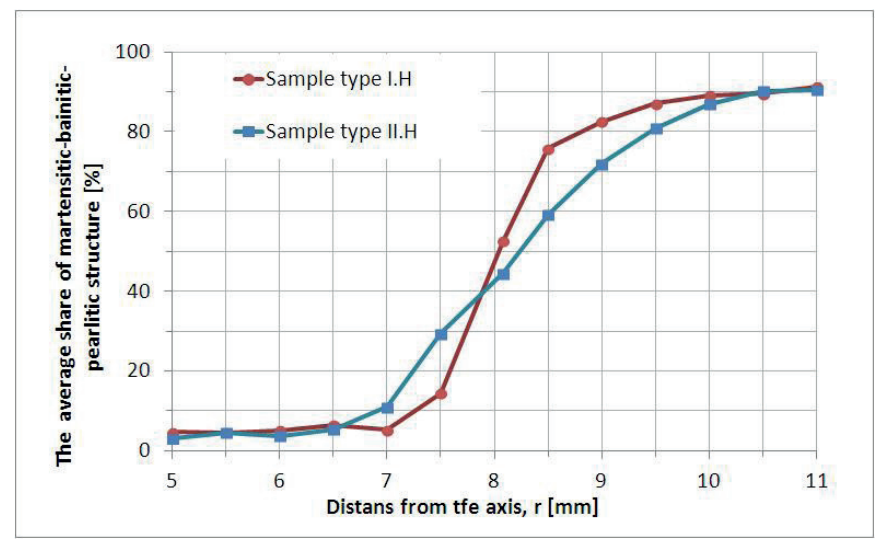

Fig. 14. The average share of martensitic-bainitic-pearlitic structure vs distance from the axis in $1 . \mathrm{H}$ and II.H type products

Both manufacturing methods produce the transition zone characterized by a well-visible graded microstructure due to the varying share of structural constituents. From Figure $13 \mathrm{~b}$ and the graph in Figure 14 it follows that the method of simultaneous charging applied in the case of type II products promotes the formation of a more extensive transition zone with milder soft core - hard surface passage. Samples taken from products of type I have a distinctly visible boundary between the two applied powder compositions (Fig. 13a).

\section{Summary}

Studies have confirmed the usefulness of the developed methods for the manufacture of cylindrical products with 
functionally graded structure and radially changing mechanical properties. Products with different structure in the outer layer and the core were obtained. The outer layer can be heat treated to further enhance the strength properties, leaving the core properties unchanged.

Microscopic examinations of the metallographic sections of products made by the technique of pre-compaction showed the presence of transverse cracks located in the sample core. The cause of those defects appearing in the area of mix A could be the internal stresses resulting from the difference in thermal and mechanical properties of the two mixes; this phenomenon is described in the literature [13]. Since products made by the simultaneous pressing were free from such cracks, the latter manufacturing technique is believed to be much more effective. It is highly advisable to perform further tests and computer simulations and explain the process of compacting and sintering as applied to the tested materials, taking into account the thermomechanical properties and their impact on the location and value of the existing internal stresses. Thorough knowledge of these phenomena will help in a correct design of the transition layer between the two materials, avoiding the occurrence of cracks.

\section{REFERENCES}

[1] L.B. Kieback, A. Neubrand, H. Riedel, Materials Science and
Engineering: A. 362,1-2, 81-106, (2003).

[2] L. A. Dobrzański, Open Access Library 8(14), (2012).

[3] J. Kusinski, S. Kac, A. Kopia, et al., A. Bull. Pol. Ac:. Tech. 60, 4, 711-728 (2013).

[4] D. Wu, X. Liang, Q. Li, L. Jiang, A. Int J Opt (2010).

[5] A. Szewczyk-Nykiel, J. Kazior, M. Nykiel, A. Czasopismo Techniczne. Mechanika, 106, . 2-M, 39-44 (2009).

[6] [6] J. Simonet, G. Kapelsk, D. Bouvard, Journal of the European Ceramic Society 27, 10, 3113-3116 (2007).

[7] S. Shindo, Y. Ueda, A. International Journal of Solids and Structures 43, 78527868 (2006).

[8] Y. Watanabe, H. Sato, Review Fabrication of Functionally Graded Materials under a Centrifugal Force, in: Dr. John Cuppoletti (Ed.), Nanocomposites with Unique Properties and Applications in Medicine and Industry, InTech, (2011).

[9] K. Zarębski, P. Putyra, A. Advanced Powder Technology 26, 401-408, (2015).

[10] [9] E. Dudrová, M. Kabátová, M. Kupková, Kov. Mater. 40, 24-34, (2002)

[11] S. Sainz, W. García, A. Karuppannagounder, F. Castro, A. Powder Metallurgy Progress 7, 121-127 (2007).

[12] M.W. Wu, K.S. Hwang, H.S. Huang; A. Metall. Mater. Trans. 38, 1598-1607, (2007).

[13] [12] M.W. Wu, K.S. Hwang, H.S. Huang, Mater. Sci. Eng. A. 527, 5421-5429 (2010).

[14] S. Shindo, Y. Ueda, A. International Journal of Solids and Structures 43, 78527868 (2006). 
